\title{
On single-phase operation of three-phase synchronous generators
}

\author{
C. Spagnolo*, S. Nuzzo**, Member, IEEE, P. Giangrande*, Member, IEEE, M. Galea*, Senior Member, IEEE, G. Serra**, Senior \\ Member, IEEE \\ *Power Electronics, Machines and Control Group, University of Nottingham, NG7 2RD UK \\ * Department of Engineering Enzo Ferrari, University of Modena and Reggio Emilia, Modena, Italy
}

\begin{abstract}
Classical synchronous generators have been used for decades in the field of power generation. The traditional manner of operation of these systems is the balanced, three phase configuration. However, recently there has been an interest in re-configuring consolidated, commercial, three phase generators to operate in single phase operation. A main driver for this phenomenon is the aim of manufacturers to extend their range of products for minimum development cost. Such an approach however brings a number of design challenges, especially in terms of the elevated damper cage currents and the negative sequence currents, when a 3-phase machine is 'forced' to operate in 1phase. This paper therefore investigates and analyses these challenges, Considering a commercial, 3-phase, $400 \mathrm{kVA}$ alternator. Detailed models, validated against experimental validation in 3-phase operation are first obtained. The machine is then re-configured to single phase operation. This paper proposes and shows how a suitable single phase loading can be found for 3-phase generators operating in single phase.
\end{abstract}

Index Terms - Synchronous Generators, Single-Phase operation, Finite Element Analysis.

\section{INTRODUCTION}

The classical, wound-field, synchronous machine is the traditional candidate for power generation applications. Considering its long history, today these machines can offer high power quality, efficiency [1] and excellent overall performance [2]. Apart from being the most common power generation source in power grids [3], the wound-field synchronous generator (SG) is also used in several marine [4], automotive and aerospace environments[5]. While these classical machines are mostly known for steady state operation with balanced loads, however there is also a growing interest in terms of their operation as single-phase $(1 \varphi)$ generators [6]. This is especially true in the large market for $1 \varphi$ operation in isolated areas where national grids are difficult to install and maintain [2]. These solutions offer a higher power-perphase ratio compared to three-phase $3 \varphi$ SGs [7] and are therefore ideal for such applications. To meet this demand for $1 \varphi$ SGs, while reducing the development costs, various SG manufacturers have recently begun to investigate the migration of their $3 \varphi$ products to $1 \varphi$ operation. This migration strategy is done by simply re-configuring a $3 \varphi$ product's winding arrangement into a $1 \varphi$ configuration, such as shown in Fig. 1.

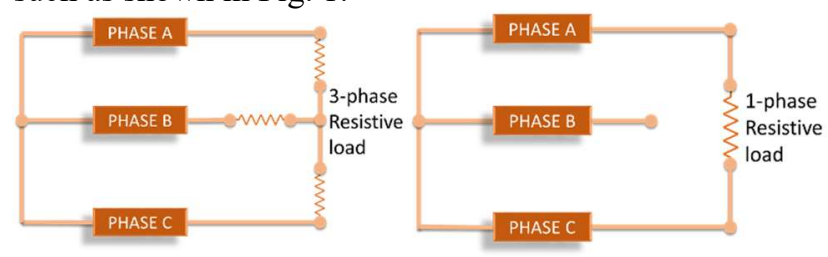

Fig. $1,3 \varphi$ and $1 \varphi$ windings configuration
It is very clear that if an existing $3 \varphi$ product is available, then very little effort is required to achieve the $1 \varphi$ version. However it does come with some technical challenges, including

1) Power rating and power density

Theoretically, the power of a $3 \varphi$ SGs working in $1 \varphi$ operation is significantly less than its original $3 \varphi$ rating. This implies that the power density of these machines is significantly poor.

2) The presence of negative sequence components

The $1 \varphi$ winding configuration represents effectively an unbalanced operating condition when current flows inside it. Hence, the effects of the armature reaction and the generator's unbalanced fields result in significant negative sequence components in the machine.

3) Elevated currents in the damper cage windings

Most classical SGs employ a damper cage winding on the rotor, which in $3 \varphi$ operation has a relatively small impact on the main performance of the machine [8]. Once the machine is in $1 \varphi$ operation, then the unbalanced loading condition in conjunction with the negative sequence field components could result in very high values of currents in the damper bars.

4) Efficiency

Due to the potentially elevated current values flowing in the damper cage during $1 \varphi$ operation, the ensuing losses can be significant leading to an overall efficiency deterioration which often obligates to de-rate the SG to avoid damaging due to high temperatures [9].

The main aim of this paper is to address the challenge highlighted in Point 1 above, while giving consideration to the ensuing issues related to Points 2), 3) and 4). In other words, it is proposed and investigated a methodology aimed at enhancing the performance in terms of power rating (and therefore power density) of a $3 \varphi$ SG operating in a $1 \varphi$ configuration. This methodology is based on the idea that the machine power rating for a $3 \varphi$ SG operating in a $1 \varphi$ configuration is mainly limited by the unbalanced currents in the damper cage winding and the ensuing thermal effects. Therefore, if the $1 \varphi$ operation was set to be constrained by the maximum allowable damper cage currents, then theoretically the power rating of the machine in $1 \varphi$ operation can be extended beyond the theoretical small portion of the original $3 \varphi$ rating. The proposed hypothesis is that the maximum $1 \varphi$ loading can be achieved when the total damper cage loss $1 \varphi$ operation is equal to the total damper cage loss in rated, $3 \varphi$ operation. This paper will therefore investigate and validate this hypothesis. As a case study, this paper considers an offthe-shelf, $400 \mathrm{kVA} \mathrm{SG}$ platform. A finite element (FE) model of the machine working in $3 \varphi$ operation is first built and validated against experimental results of the SG case 
study. The same model is then modified to a $1 \varphi$ version and thus the $1 \varphi$ loading that results in the same damper cage loss as for the rated $3 \varphi$ operation can be found. The operational characteristics of the machine at this load point are then mapped out. The prototype machine is then reconfigured for $1 \varphi$ operation and tested at the loading point identified by the model in $1 \varphi$ operation. The experimental results and the FE results are then compared to highlight the validity of the proposed hypothesis and methodology.

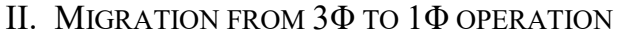

While classical SGs working in $1 \varphi$ operation are not a very common sight, however there have been some cases in literature where this has been investigated [10, 11]. Their proven performance and voltage regulation capabilities make it a good candidate when an efficient, reliable and power quality compliant product is required for electric $1 \varphi$ energy generation [12]. An optimal way how to do this is as explained in [13], where the idea is to connect two phases in series while leaving the third one open circuited, in order to exploit most of the copper material already available within the slots. With this configuration, the $1 \varphi$ output power $P_{1 \varphi}$ is given by the product of the line-to-line voltage and the current flowing inside the 2 connected phases. Thus, the ratio between the $3 \varphi$ power $\mathrm{P}_{3 \varphi}$ and $\mathrm{P}_{1 \varphi}$ can be written as in (1).

$$
\frac{P_{1 \varphi}}{P_{3 \varphi}}=\frac{1}{\sqrt{3}}=0.578
$$

When it is assumed that the machine design features allow for equal losses in the stator windings for $1 \varphi$ and $3 \varphi$ cases, the current ratio shown in (2) would then be feasible and thus the power ratio is as given in (3).

$$
\begin{gathered}
\frac{I_{1 \varphi}}{I_{3 \varphi}}=\sqrt{\frac{3}{2}}=1.225 \\
\frac{P_{1 \varphi}}{P_{3 \varphi}}=\frac{V_{l l} I_{1 \varphi}}{\sqrt{3} V_{l l} I_{3 \varphi}}=\frac{1}{\sqrt{2}}=0.717
\end{gathered}
$$

In (2) and (3), $\mathrm{V}_{11}$ is the line-to-line voltage and $\mathrm{I}_{3 \varphi}$ and $I_{1 \varphi}$ are the output currents for the $3 \varphi$ and $1 \varphi$ conditions, respectively. Having given the basic relationships between $3 \varphi$ and $1 \varphi$ a fundamental step in this transformation process consists in determining the value of $\mathrm{I}_{\mathrm{F} 1 \varphi}$ needed to feed different loads while keeping the output voltage constant. Starting from the $\mathrm{BH}$ characteristic of the laminations used for the stator and rotor cores and given the geometrical dimensions, it becomes possible to calculate the magneto-motive-force ( $\mathrm{mmf}$ ) drops along the main flux lines. In Fig. 2, the Arnold-Blondel diagram can be observed, where $\Phi_{\mathrm{M}}$ is the magnetization flux, $\Phi_{\mathrm{F}}$ is the excitation flux, $\mathrm{L}_{\mathrm{d}} \mathrm{I}_{\mathrm{d}}$ and $\mathrm{L}_{\mathrm{q}} \mathrm{I}_{\mathrm{q}}$ are the $\mathrm{d}$-axis and $\mathrm{q}$-axis fluxes.

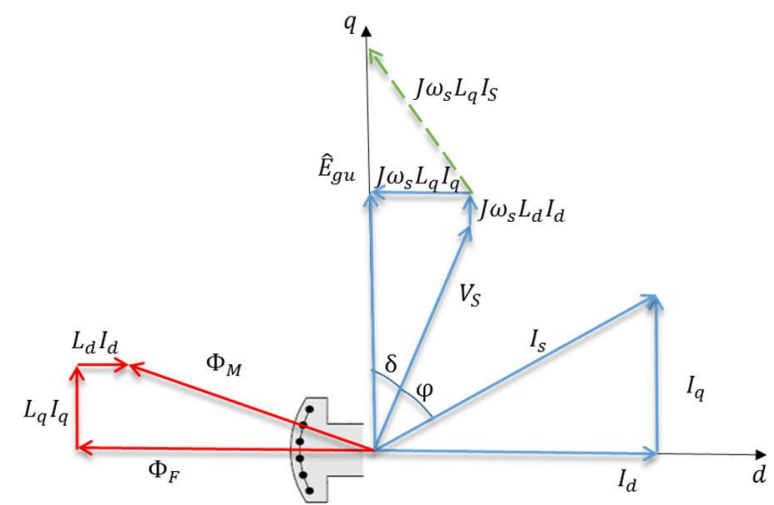

Fig. 2. Arnold-Blondel diagram of salient pole wound rotor SG

The $\mathrm{d}$ - and q-axis currents $\mathrm{I}_{\mathrm{d}}$ and $\mathrm{I}_{\mathrm{q}}$ can be calculated as in (4) and (5) respectively. Then, the no-load electromotive force (emf) value of the unsaturated machine Egu can be determined as in (6).

$$
\begin{gathered}
I_{d}=I_{S} \sin (\delta+\varphi) \\
I_{q}=I_{S} \cos (\delta+\varphi) \\
\hat{E}_{g u}=V_{S}+j X_{q} I_{q}+j X_{d} I_{d}
\end{gathered}
$$

In (4)-(6), $X_{q}$ and $X_{d}$ are the unsaturated reactances of $\mathrm{q}$ - and d-axis respectively, VS is the stator voltage vector, $\delta$ is the angle between $\mathrm{E}_{\mathrm{gu}}$ and VS, while $\varphi$ represents the angle between $V_{S}$ and $I_{S}$. It becomes now possible to determine the value of the mmf that needs to be supported by the rotor field when the machine is unsaturated. The detailed analytical calculation of all the values of the ampere-turns is shown in [7] and here the final expression is only provided in (7). Here, it can be noticed that the total $1 \varphi$ and $3 \varphi$ ampere-turns, Ftot- $1 \varphi$ and Ftot- $3 \varphi$, are related through the constant value equal to $\sqrt{ } 3$. This same relationship can be then written between the $1 \varphi$ and the 3 $\varphi$ field currents.

$$
F_{t o t-1 \varphi}=\frac{F_{t o t-3}}{\sqrt{3}}
$$

Having proven that the field winding current needed for the $1 \varphi$ operation (when 2 phases are series-connected and 1 phase disconnected and the line-to-line voltage in $1 \varphi$ corresponds the phase-to-neutral voltage in $3 \varphi$ ) is $\sqrt{3}$ smaller than that necessary for the corresponding $3 \varphi$ operation this scaling factor can be employed to analyse the machine operation at different $1 \varphi$ loading conditions. It is worth to remark that in this case the line-to-line voltage is $\sqrt{3}$ smaller compared with the $3 \varphi$ one in star connection. However, the experimental campaign carried out within this paper keeps the single-phase output voltage at $400 \mathrm{~V}$. 


\section{THE CONSIDERED SG PLATFORM}

As mentioned above, this work adopts an off-the-shelf, $400 \mathrm{kVA}$, salient pole $\mathrm{SG}$ as a case study platform. A picture of the machine is shown in Fig. 3, and its main operational parameters and specifications are given Table I.

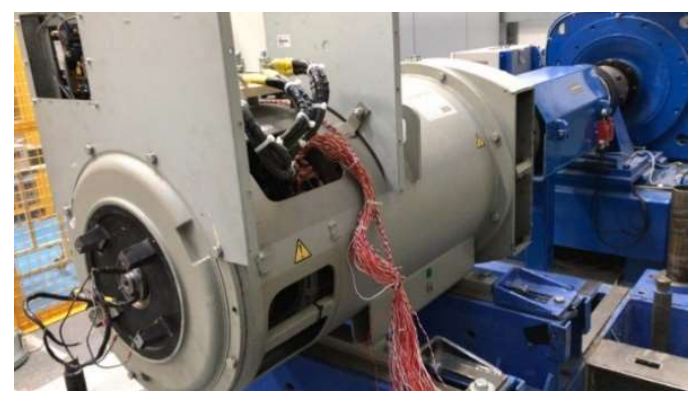

Fig. 3. The considered $400 \mathrm{kVA}$ synchronous generator.

TABLE I

MAIN PARAMETERS OF THE CONSIDERED PLATFORM

\begin{tabular}{|c|c|}
\hline Machine Parameter & Parameter Value \\
\hline Rated apparent power & $400 \mathrm{kVA}$ \\
\hline Rated voltage & $400 \mathrm{~V}$ \\
\hline Power factor & 0.8 \\
\hline Frequency & $50 \mathrm{~Hz}$ \\
\hline Number of poles & 4 \\
\hline Number of slots & 48 \\
\hline Outer diameter & $500 \mathrm{~mm}$ \\
\hline Axial length & $500 \mathrm{~mm}$ \\
\hline
\end{tabular}

The stator winding of the machine has a double-layer structure and features a shortened pitch of 1/3-rd of the pole pitch to remove the $3 \mathrm{rd}$ order harmonics. The machine has 2 circuits in parallel on the stator winding, each of them characterized by 8 coils. Another major design feature is the stator slot skewing [14] to attenuate the slotting harmonics. The rotor is a salient-pole one and is equipped with 6 damper bars, implemented symmetrically per pole [15]. All these characteristics can be observed in the 2D cross-section of the machine shown in Fig. 4, where one of the stator phases is highlighted to show the winding configuration.

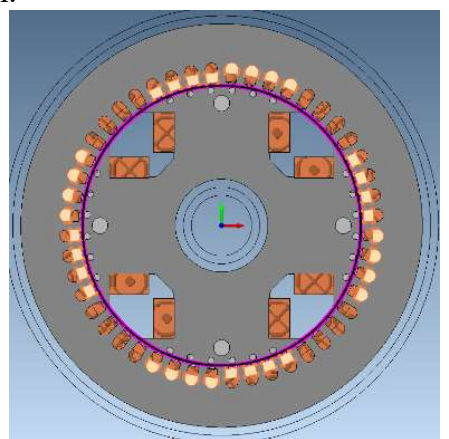

Fig. 4. 2D cross-section of the studied SG.

A FE model of this machine was built and validated against experimental results obtained on the prototype. The full operational analysis of the machine and the validation of the FE model is presented in [7]. To replicate these analyses here would go beyond the scope of this paper, however, since the work in this paper relies heavily on the loss characteristics of this machine, then it was felt important to include the loss analysis of the machine.
Figures 5 and 6 give the copper and the iron loss values of the SG under several loading conditions and power factors, respectively. These figures compare the results of the FE model shown in Figure 4 against the experimental measures on the machine shown in Fig. 3. A perfect match between FE and the experimental copper losses can be observed in Fig. 5, while an error of $\approx 10 \%$ is found in terms of iron losses, as seen in Fig. 6. In particular, to be coherent with the experimental tests [16], this error is calculated at no-load. The rotor, stator and damper cage losses are separately evaluated via $\mathrm{FE}$ analysis as a physical segregation of the experimental iron losses is virtually impossible.

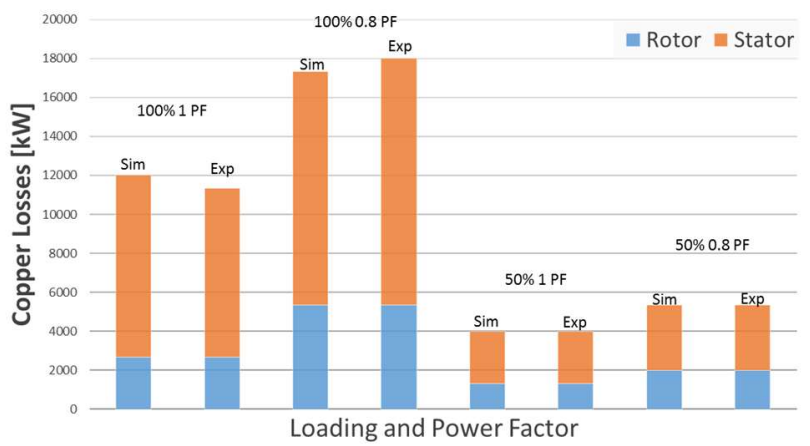

Fig. 5. FE vs. experimental copper losses at different loadings and power factor values.

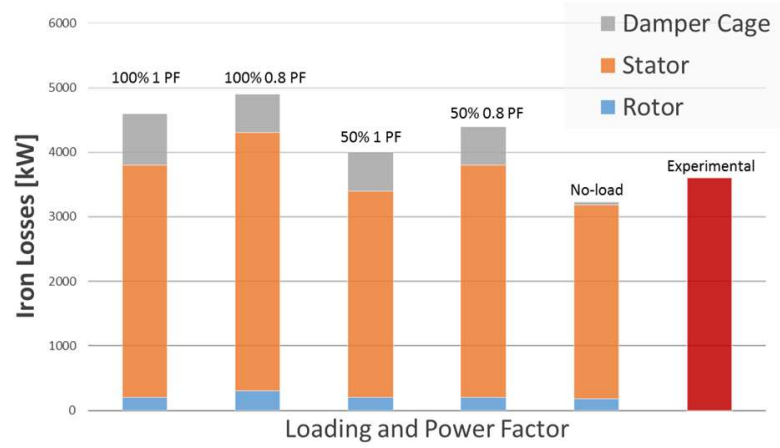

Fig. 6. FE vs. experimental iron losses at different loadings and power factor values

At full-load (0.8 power factor and $100 \%$ loading), the total copper and iron losses of the machine are $18 \mathrm{~kW}$ and $5.3 \mathrm{~kW}$ respectively. These values of loss obtained by FE and validated experimentally will then be used in the next section as the main constraint to the SG operating in a $1 \varphi$ configuration. The maximum $1 \varphi$ loading that the machine can supply for the same amount of losses will be found and the machine operated at this loading point.

\section{SG OPERATING IN $1 \Phi$}

The FE model shown in Fig. 4 is modified to operate in $1 \varphi$ mode. This is done by modifying the stator circuit connections to the configuration shown in Fig. 1, where 2 phases are in series (A and $\mathrm{C}$ in the figure) and connected through a purely resistive load (i.e. unity power factor), while the third is left disconnected. As described above, the hypothesis behind this paper is that the $1 \varphi$ operation of a classical $3 \varphi$ SG can be enhanced if the main limiting factor is considered to be the losses in the damper cage winding. However, as the first stage of the analysis, the 
machine is investigated for the theoretical $1 \varphi$ operation, i.e. the model is first run at the rated $1 \varphi$ operation, as obtained from (1). The expectation here is that the power performance will be good, but the losses in the damper cage winding due to the unbalanced currents will be excessively high. For the model to run with a loading condition as achieved by (1), then a resistive load that represents this loading point is determined and implemented within the FE model. This loading point requires a field current that is $\sqrt{ } 3$ less than the rated $3 \varphi$ field current. This is in line with the analytical description of $1 \varphi$ operation given in Section II.

Table II shows the results of the model operating at this point, while Fig. 7 illustrates the output voltage and current waveforms registered on the load [17].
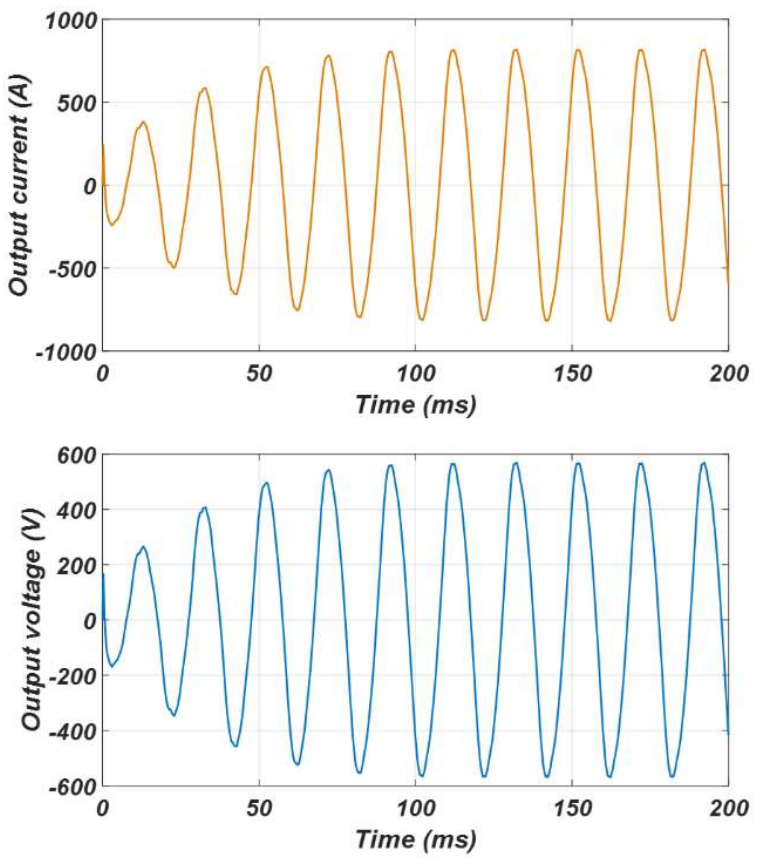

Fig. 7. FE voltage and current waveforms obtained at rated conditions in $1 \varnothing$ operation.

TABLE II

FE RESULTS OF THE CONSIDERED SG OPERATING IN STANDARD 1PH CONDITION AT MAXIMUM POWER RATING

\begin{tabular}{|c|c|}
\hline $\boldsymbol{V}_{\boldsymbol{r m s}}$ & $401.1 \mathrm{~V}$ \\
\hline $\boldsymbol{I}_{\boldsymbol{r m s}}$ & $577.1 \mathrm{~A}$ \\
\hline $\boldsymbol{P}$ & $231 \mathrm{~kW}$ \\
\hline $\boldsymbol{I}_{\boldsymbol{F}_{1-\text { phase }}}$ & $28.9 \mathrm{~A}$ \\
\hline
\end{tabular}

For this operating condition, Table III tabulates only the losses induced inside the bars of one of the salient poles (given the odd symmetry characterizing the machine). A map of the field lines' distribution and of the current density inside the bars is plotted in Fig. 8, where the nonuniform current density distribution within the bars can be observed. From Table III, it can be noticed that the total damper cage loss for this operating $1 \varphi$ condition amounts to $\approx 7.35 \mathrm{~kW}$ which as expected, is actually one order of magnitude higher than the value (i.e. $\approx 600 \mathrm{~W}$ ) found under the rated full-load $3 \varphi$ operation (see Fig. 6). This confirms that this $1 \varphi$ loading condition is not suitable for the machine and therefore the FE model must be used to identify the loading condition that results in a similar amount of losses in the damper cage winding for $1 \varphi$ and $3 \varphi$ operation.

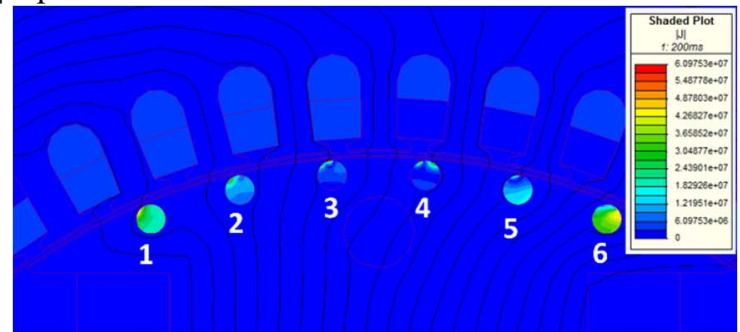

Fig. 8, Field lines' distribution and current density in the damping bars of one salient pole.

TABLE III

LOSSES IN THE DAMPER BAR IN SINGLE-PHASE AT RATED CONDITIONS

\begin{tabular}{|l|l|}
\cline { 2 - 2 } \multicolumn{1}{c|}{} & Losses [W] \\
\hline Bar1.1 & 270 \\
\hline Bar1.2 & 149 \\
\hline Bar1.3 & 123 \\
\hline Bar1.4 & 92 \\
\hline Bar1.5 & 152 \\
\hline Bar1.6 & 1051 \\
\hline
\end{tabular}

To find the optimal loading condition, the FE model is used to run various loading conditions. The loading values are chosen according to the available experimental platform (see next section). In Fig. 9, the field current vs. the loading level (at rated output line-to-line voltage) is provided. Table IV gives the value of the $3 \varphi$ and $1 \varphi$ losses in the damper cage and the total losses of the machine at different power ratings, evaluated via the FE model described above. From the table, it can be noticed that for higher values of loadings, the damper cage loss becomes more dominant for the $1 \varphi$ operation, as expected.

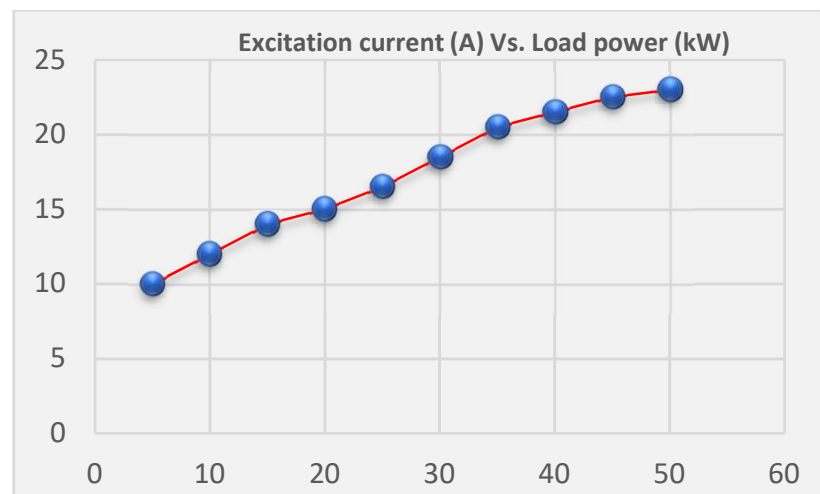

Fig. 9. Values of the field current at different loading conditions with constant output voltage

TABLE IV

LOSSES IN THE DAMPER BARS AND TOTAL LOSSES AT DIFFERENT LOAD

\begin{tabular}{|c|c|c|c|c|}
\hline $\begin{array}{l}\text { Power } \\
{[\mathrm{kW}]}\end{array}$ & $\begin{array}{l}1 \varphi \text { Damper } \\
\text { cage Loss [W] }\end{array}$ & $\begin{array}{l}1 \varphi \text { Total } \\
\text { Losses [W] }\end{array}$ & $\begin{array}{l}3 \varphi \text { Damper } \\
\text { loss [W] }\end{array}$ & $\begin{array}{l}3 \varphi \\
\text { Total } \\
\text { losses } \\
{[\mathrm{W}]}\end{array}$ \\
\hline 4.63 & 212 & 2778 & 204 & 2624 \\
\hline 9.26 & 218 & 2786 & 206 & 2900 \\
\hline 16.20 & 236 & 2889 & 217 & 3043 \\
\hline
\end{tabular}




\begin{tabular}{|l|l|l|l|l|}
\hline 20.83 & 260 & 2998 & 227 & 3126 \\
\hline 25.46 & 328 & 3393 & 240 & 3225 \\
\hline 30.09 & 428 & 3794 & 242 & 3288 \\
\hline 34.72 & 564 & 4221 & 274 & 3400 \\
\hline 41.67 & 619 & 4354 & 295 & 3483 \\
\hline 46.30 & 695 & 4513 & 318 & 3584 \\
\hline 50.93 & 837 & 4920 & 347 & 3685 \\
\hline
\end{tabular}

Using Table IV, then it can be identified that the losses inside the damper cage at $1 \varphi$ operation are similar to those induced at full load in $3 \varphi$ conditions (see Fig. 6), when the load is at $41.67 \mathrm{~kW}$. Having identified the most suitable $1 \varphi$ load condition, then the next section is focused on validating the results from the $1 \varphi$ model by comparison against experimental measurements performed on a $1 \varphi$ version of the case study machine.

\section{EXPERIMENTAL RESULTS}

The $400 \mathrm{kVA}$ generator shown in Figures 2 and 3 is modified to operate in $1 \varphi$ operation, as in Fig. 1. This is achieved quite simply by reconfiguring the winding terminals of the machine in the desired configuration as explained in Section I. i.e. with phase A and C connected in series. With the machine configuration in place, then a testing regime aimed at covering the same loading conditions as given in Table IV for the FE model are done experimentally. The SG field current is provided by a DC power supply in current-mode control and "manually" adjusted to keep the output terminal voltage equal to its rated value of $400 \mathrm{~V}$ while the load is varied. The stator terminals are connected to a purely resistive load bank, remotely controllable for modifying the loading condition from $4.63 \mathrm{~kW}$ and $50.93 \mathrm{~kW}$. Table V shows a comparison between $\mathrm{FE}$ and experimental results relative to the voltage and current values at different loading operations. A very good match can be observed at the various loading conditions investigated. Given that the main objective is that of proving the concept on the established optimal loading of $41.67 \mathrm{~kW}$, the copper and iron losses are reported in Table VI at this specific SG $1 \varphi$ loading operation. The iron losses are considered equal to the value shown in Fig. 6, as the standard test procedure [16] used to determine them assumes a constant value for the operating loadings of the SG. Since the damper cage losses determination is a very difficult task to perform experimentally, they are taken equal to the values obtained via the FE model $(619 \mathrm{~W})$. This is done to 1) fairly compare the FE and experimental results at $1 \varphi$ operation and 2) to prove that the overall losses produced in $1 \varphi$ condition (at $41.67 \mathrm{~kW}$ ) can be safely sustained by the machine and most importantly by the damper winding.

TABLE V

MACHINE CURRENT AND VOLTAGE VALUES CALCULATED WITH EXPERIMENTAL TESTS

\begin{tabular}{|l|l|l|l|l|}
\hline \multirow{2}{*}{$\begin{array}{l}\text { Load Level } \\
{[\mathrm{kW}]}\end{array}$} & \multicolumn{3}{|c|}{ Current [A] } & \multicolumn{2}{c|}{ Voltage [V] } \\
\cline { 2 - 5 } & FE & Exp. & FE & Exp. \\
\hline
\end{tabular}

\begin{tabular}{|l|l|l|l|l|}
\hline 4.63 & 11.32 & 11.58 & 409 & 400 \\
\hline 9.26 & 22.75 & 23.15 & 407 & 400 \\
\hline 16.20 & 39.6 & 40.5 & 410 & 400 \\
\hline 20.83 & 51.5 & 52.08 & 405 & 400 \\
\hline 25.46 & 62.8 & 63.65 & 406 & 400 \\
\hline 30.09 & 75.6 & 75.23 & 398 & 400 \\
\hline 34.72 & 87.1 & 86.8 & 399 & 400 \\
\hline 41.67 & 103.91 & 104.18 & 401 & 400 \\
\hline 46.30 & 117.21 & 115.75 & 395 & 400 \\
\hline 50.93 & 126.07 & 127.33 & 404 & 400 \\
\hline
\end{tabular}

TABLE VI

EXPERIMENTAL LOSSES AT 40KW

\begin{tabular}{|l|l|l|l|l|}
\hline $\begin{array}{l}\text { Load } \\
{[\mathrm{kW}]}\end{array}$ & $\begin{array}{l}\text { Copper } \\
\text { losses }[\mathrm{W}]\end{array}$ & $\begin{array}{l}\text { Iron losses } \\
{[\mathrm{W}]}\end{array}$ & $\begin{array}{l}\text { Bar losses } \\
{[\mathrm{W}]}\end{array}$ & $\begin{array}{l}\text { Total } \\
\text { losses }[\mathrm{W}]\end{array}$ \\
\hline 41.67 & 450 & 3850 & 619 & 4919 \\
\hline
\end{tabular}

It can be observed from the comparison between the total losses of Table IV and Table VI, at $41.67 \mathrm{~kW}$, that there is an error difference of $11.5 \%$. This highlights the excellent similarity between the predicted and measure results, even when considering the notoriously difficult task of predicting losses accurately. To further strengthen these concepts, thermal steady state measurements were carried out to verify that the rotor temperatures do not exceed the rated limits, when the machine operates at the identified $1 \varphi$ loading level. Besides the thermocouples located on the SG stator, a number of additional temperature sensors (6 along the active sides and 2 onto the end parts of the rotor field winding - this is done for 2 salient poles) were located onto the rotor. A set of acquisition devices (yoyos) mounted on the machine shaft and thus synchronously rotating with the machine were used for reading the rotor temperatures. In Fig. 10, the yoyos used for such purpose are shown.

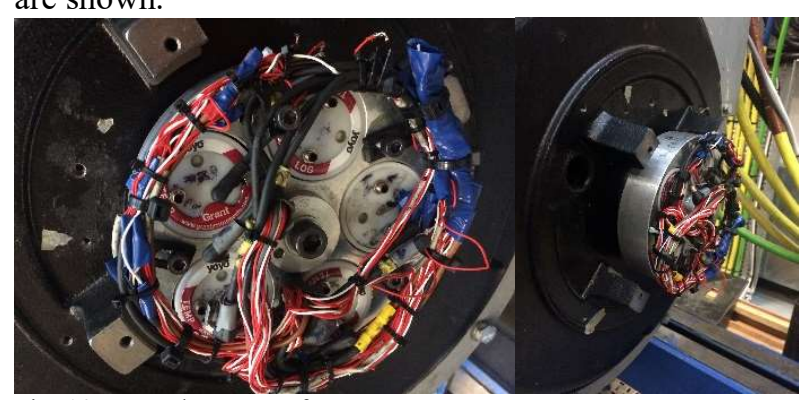

Fig. 10, yoyos log set-up for rotor temperature measurement.

The experimental tests were performed running the machine in $1 \varphi$ configuration with the resistive load bank set at $41.67 \mathrm{~kW}$ and observing that after 6 hours (i.e. the time needed to reach the thermal steady-state) the rotor temperatures raised up to $80^{\circ}$, which is well below the thermal limit specified in the machine datasheet (i.e. $130^{\circ}$ ). This concept can be seen in Fig. 11, where the trend of the rotor temperatures is plotted against the core length.

Due to the location of the cooling fan, whose equivalent position is on the negative values of the $x$-axes of the figures above, the hot spot is decentralized from the center of the machine core $(250 \mathrm{~mm})[18,19]$. The results above demonstrate that the considered $\mathrm{SG}$ is able to safely operate in $1 \varphi$ conditions when supplies loads of $41.67 \mathrm{~kW}$. 


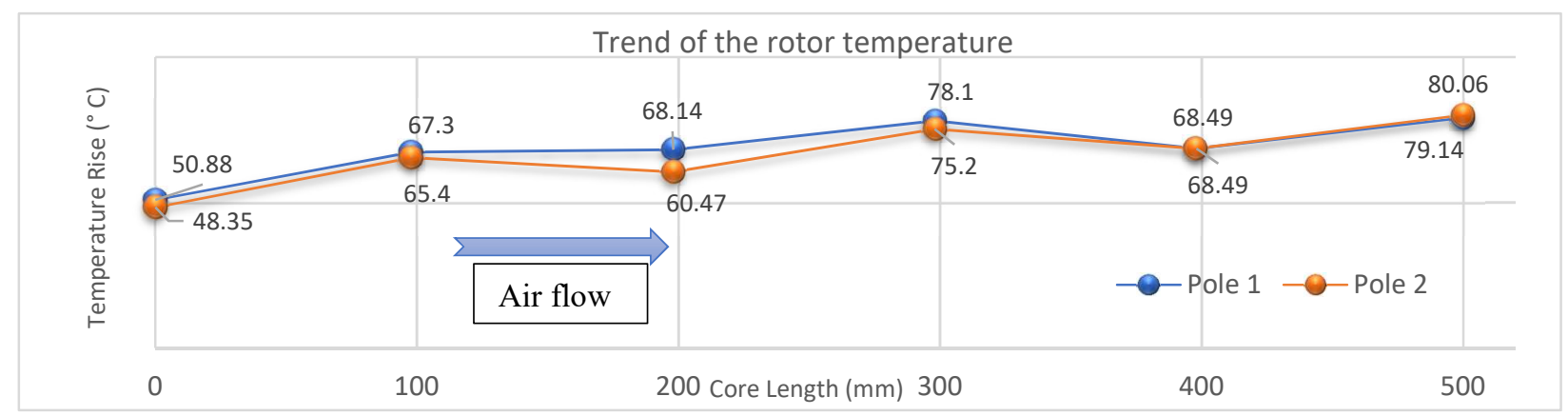

Fig. 11, Rotor temperature characteristic along the axial length of the rotor poles 1 and 2

\section{CONCLUSION}

The aim of this paper is to enhance the performance of an off-the-shelf, 3-phase, 400 kVA salient-pole synchronous generator when operating in single-phase. This particular unbalanced operation is critical from a thermal management perspective, due to the negative sequence field inducing very high currents in the machine damper winding. This work first presents a full experimental validation of the FE model purposely built to analyse the 3-phase operation of the considered generator. The analytical background behind the machine operational switch from 3-phase to 1-phase is then investigated. The validated models are then used to study the single-phase operation. A most suitable single-phase loading is found, based upon the concept of maintaining the damper cage loss equal to the value registered at rated, full-load threephase condition. Experimental tests have been finally performed at the optimal loading of $41.67 \mathrm{~kW}$, at $400 \mathrm{~V}$ and unity power factor. Also the rotor temperature profiles has been registered during this test showing a safe operation of the machine. The methods and the findings detailed in this paper have proven that an optimal utilization of 3-phase synchronous generators operating at 1-phase is achievable without relying upon simplified and/or semi-empirical considerations.

\section{ACKNOWLEDGEMENT}

This work is funded by the Institute for Aerospace Technology (IAT) at the University of Nottingham. This work was also supported by the Ningbo 3315 Innovation Team Scheme under Grant 2018A-08-C.

\section{REFERENCES}

1. $\quad$ El-Refaie, A.M., Motors/generators for traction/propulsion applications: A review. IEEE Vehicular Technology Magazine, 2013. 8(1): p. 90-99.

2. Nuzzo, S., et al., Analysis, Modeling, and Design Considerations for the Excitation Systems of Synchronous Generators. IEEE Transactions on Industrial Electronics, 2018. 65(4): p. 2996-3007.

3. Sulligoi, G., A. Vicenzutti, and R. Menis, All-Electric Ship Design: From Electrical Propulsion to Integrated Electrical and Electronic Power Systems. IEEE Transactions on Transportation Electrification, 2016. 2(4): p. 507-521.

4. Tessarolo, A., C. Bassi, and D. Giulivo, Time-Stepping FiniteElement Analysis of a 14-MVA Salient-Pole Shipboard Alternator for Different Damper Winding Design Solutions.
IEEE Transactions on Industrial Electronics, 2012. 59(6): p. 2524-2535.

5. Madonna, V., P. Giangrande, and M. Galea, Electrical Power Generation in Aircraft: Review, Challenges, and Opportunities. IEEE Transactions on Transportation Electrification, 2018. 4(3): p. 646-659.

6. Chrin, P., et al. Modeling of 3-phase induction machine as single phase generator for electricity generation from renewable energies in rural areas. in 2015 IEEE International Electric Machines \& Drives Conference (IEMDC). 2015.

7. Spagnolo, C., et al. Analysis of salient-pole synchronous generators operating in single-phase condition. in 2017 IEEE Workshop on Electrical Machines Design, Control and Diagnosis (WEMDCD). 2017.

8. $\quad$ Nuzzo, S., et al., Improved Damper Cage Design for SalientPole Synchronous Generators. IEEE Transactions on Industrial Electronics, 2017. 64(3): p. 1958-1970.

9. Sciascera, C., et al. Lifetime consumption and degradation analysis of the winding insulation of electrical machines. in 8th IET International Conference on Power Electronics, Machines and Drives (PEMD 2016). 2016.

10. Fukami, T., et al., Performance analysis of a self-regulated self-excited single-phase induction generator using a threephase machine. IEEE Transactions on Energy Conversion, 1999. 14(3): p. 622-627.

11. Kahourzade, S., W.L. Soong, and P. Lillington, Single-Phase Loading Behavior of the Isolated 3ph Spoke Interior Permanent-Magnet Generator. IEEE Transactions on Industry Applications, 2017. 53(3): p. 1860-1869.

12. Wang, Y., et al. Sensitivity analysis for performance and power density improvements in salient-pole synchronous generators. in 2017 IEEE Workshop on Electrical Machines Design, Control and Diagnosis (WEMDCD). 2017.

13. Madawala, U.K., et al., Modeling and Analysis of a Novel Variable-Speed Cage Induction Generator. IEEE Transactions on Industrial Electronics, 2012. 59(2): p. 10201028.

14. Nuzzo, S., et al., A Fast Method for Modeling Skew and Its Effects in Salient-Pole Synchronous Generators. IEEE Transactions on Industrial Electronics, 2017. 64(10): p. 76797688.

15. Nuzzo, S., et al., A Methodology to Remove Stator Skew in Small-Medium Size Synchronous Generators via Innovative Damper Cage Designs. IEEE Transactions on Industrial Electronics, 2019. 66(6): p. 4296-4307.

16. 60034-2-1:2014, B.E., Rotating electrical machines. Standard methods for determining losses and efficiency from tests (excluding machines for traction vehicles). 2014: p. 90.

17. Gyselinck, J.J.C., L. Vandevelde, and J.A.A. Melkebeek, Multi-slice FE modeling of electrical machines with skewed slots-the skew discretization error. IEEE Transactions on Magnetics, 2001. 37(5): p. 3233-3237.

18. Dave Staton, D.H.a.M.P., Thermal Behaviour of Electrical Motors - An Analytical Approach. CWIEME, Berlin, May 2009, 2009.

19. Boglietti, A., et al., Evolution and Modern Approaches for Thermal Analysis of Electrical Machines. IEEE Transactions on Industrial Electronics, 2009. 56(3): p. 871-882. 